\title{
A Validated HPLC Method for the Determination of Vitamin K in Human Serum - First Application in a Pharmacological Study
}

\author{
Milka Marinova $^{\#, 1,2}$, Dieter Lütjohann*,\#,2, Philipp Westhofen ${ }^{1}$, Matthias Watzka ${ }^{1}$, Olof Breuer ${ }^{2}$ and \\ Johannes Oldenburg ${ }^{1}$
}

${ }^{I}$ Institute of Experimental Hematology and Transfusion Medicine, University of Bonn, Germany; ${ }^{2}$ Institute of Clinical Chemistry and Clinical Pharmacology, University of Bonn, Germany

\begin{abstract}
Dietary phylloquinone (vitamin K1) is considered to be a major determinant of human vitamin K status. For this reason, measurements of plasma vitamin $\mathrm{K}$ concentrations provide a useful tool of vitamin $\mathrm{K}$ status in man. There is a growing interest in the role, biochemical function, and metabolism of vitamin $\mathrm{K}$ in vivo.

A modified reversed phase-HPLC method with fluorescence detection after post-column zinc reduction in serum samples was validated for vitamin $\mathrm{K}$ analysis. Two human volunteers were investigated after p.o. and i.v. administration of $2 \mathrm{mg}$ Konakion ${ }^{\circledR}$ MM. Blood samples were collected periodically after administration and subjected to pharmacokinetic evaluation.

High sensitivity, analytical recoveries, accuracy and calibration curves linearities could be reached. Our results showed an overall coefficient of variation of less than $10 \%$ for the intra- and interday reproducibility, while the recovery ranged from $91 \%$ to $114 \%$. The limit of detection and quantification were $0.015 \mathrm{ng} \mathrm{mL}^{-1}$ and $0.15 \mathrm{ng} \mathrm{mL}^{-1}$, respectively. Long-term stability was verified over a period of six months. The accuracy was proven by good results from external quality assurance.

The observed pharmacokinetic differences indicate significant intra- and inter-individual variance of vitamin $\mathrm{K}$ fate in the human body.

This highly accurate, robust and reliable method is appropriate for the evaluation of vitamin $\mathrm{K}$ status in human serum. The ability to determine vitamin $\mathrm{K}$ has the potential to improve pharmacokinetic studies.
\end{abstract}

Keywords: Chromatography, coagulation, Konakion, lipids, menaquinone-4, pharmacokinetics, phylloquinone.

\section{INTRODUCTION}

Vitamin $\mathrm{K}$ is an essential cofactor in the synthesis of active blood-clotting factors II, VII, IX, X, protein C and protein $\mathrm{S}$ as well as non-coagulation proteins such as osteocalcin and matrix Gla protein $[1,2]$. The vitamin $\mathrm{K}$-dependent step is a posttranslational carboxylation reaction of protein precursors by converting glutamic acid residues (Glu) to $\gamma$-carboxyglutamic residues (Gla) [3]. This provides an efficient chelating site for calcium-binding essential for protein-membrane interaction. The conversion of Glu to Gla-residues in vitamin K-dependent (VKD) proteins is linked to the vitamin $\mathrm{K}$ cycle which recovers vitamin $\mathrm{K}$ from its epoxide form for reuse in carboxylation [4-6]. When $\gamma$-carboxylation is impaired because of deficiency or antagonism of vitamin $\mathrm{K}$, inert precursors of VKD proteins, known as Proteins Induced by Vitamin $\underline{\mathrm{K}} \underline{\mathrm{A}} \underline{\mathrm{V}}$enceorAntagonism (PIVKA), are released into the blood [7].

*Address correspondence to these authors at the Institute of Clinical Chemistry and Clinical Pharmacology, University Clinic Bonn, Bonn, Germany, Sigmund- Freud-Str. 25, D-53127 Bonn, Germany; Tel: +4922828714027; Fax: +4922828716047; E-mail: dieter.luetjohann@ukb.uni-bonn.de

"both authors contributed equally.
The major dietary form of vitamin $\mathrm{K}$ is phylloquinone (vitamin K1) produced by green plants and present in foods of plant origin, especially in green leafy and flower vegetables [8]. Menaquinones (vitamin K2) are primarily of bacterial origin. Menaquinone-4 (MK-4) is not a major constituent of bacterial production; instead it is alkylated from menadione present in animal feeds or is the product of tissuespecific conversion directly from dietary phylloquinone $[9$, 10]. Vitamin $\mathrm{K}$ is normally absorbed with other fat-soluble vitamins predominantly from the proximal intestine [11]. This intestinal absorption involves the solubilization of vitamin $\mathrm{K}$ into mixed micelles composed of bile salts and products of pancreatic lipolysis and is known to be impaired in patients with malabsorption or other gastrointestinal disorders, including biliary atresia, cystic fibrosis, celiac disease, and short bowel syndrome [12]. Vitamin $K$ is not known to have a carrier protein; instead, triglyceride-rich lipoproteins (TRL), primarily chylomicron remnants and very low-density lipoproteins (VLDL), are thought to be the main transporters of phylloquinone [13-15]. Vitamin $\mathrm{K}$ is extensively metabolized in the liver and excreted in the urine $(20 \%)$ and bile (40\%).

When vitamin $\mathrm{K}$ deficiency caused by e.g. poor oral intake, severe cholestasis, treatment with broad spectrum antibiotics, contributes to major coagulopathy, it has been rec- 
ommended to supplement vitamin $\mathrm{K} 1$, while the administration route of choice depends on the patient's clinical situation. The commonly prescribed formulation of vitamin $\mathrm{K} 1$ is Konakion $^{\circledR}$ (F.Hoffmann-La Roche Ltd, Grenzach-Wyhlen, Germany), which contains its synthesized form phytomenadione solubilized in glucocholate-phosphatidylcholine mixed micelles (MM) $[16,17]$. Konakion $^{\circledR}$ MM can be administered orally, intramuscularly, and intravenously and is used for prophylaxis and therapy of vitamin $\mathrm{K}$ deficiency bleeding in newborns.

Dietary phylloquinone is considered to be the major determinant of human vitamin $\mathrm{K}$ status. Hence, circulating phylloquinone concentrations in human plasma reflect dietary intake over the previous $24 \mathrm{~h}$, and have high intra- and interindividual variation compared to other fat-soluble vitamins [18]. Less is known about the diet-plasma associations for menaquinones. For this reason, measurements of plasma phylloquinone concentrations provide one of several alternative useful indices of vitamin $\mathrm{K}$ status in man. Vitamin $\mathrm{K}$ serum determination is impeded due to the low phylloquinone concentration commonly found in plasma (0.3-2.7 nmol/L) [19], compared to other endogenous lipids. Plasma levels of menaquinone-4 are normally too low to be measured. In previous reports, electrochemical and fluorescence detection after post-column reduction has provided sufficient sensitivity and selectivity to enable phylloquinone analysis [20-22]. Our aim was to improve the sensitivity by modifying some steps so as to obtain a simple and fast method, suitable for the routine analysis of plasma or serum vitamin $\mathrm{K}$. Validation evidence and quality assurance performance are also required in order to prove and warrant the practical applicability of the method for vitamin $\mathrm{K}$ serum determination. The first application of the HPLC method in a pharmacological study on the pharmacokinetics of vitamin $\mathrm{K} 1$ is also presented.

\section{MATERIALS AND METHODOLOGY}

\section{Instrumentation}

The isocratic HPLC system (VWR, Darmstadt, Germany) consisted of separation Hitachi modules with in-line vacuum degasser, L-2130 Pump, L-2200 Autosampler, L-2300 Column Oven and L-2485 Fluorescence Detector, all controlled by Elite LaChrom software (V.3.1.7.). A Nucleodur C18 Gravity column (3 mm i.d. x $100 \mathrm{~mm}$ length, 3 $\mu \mathrm{m}$ particle size) was used for separation. During analysis the column temperature was maintained at $22^{\circ} \mathrm{C}$, the autosampler temperature was kept at $15^{\circ} \mathrm{C}$. A $10 \mathrm{~cm}$ long, postcolumn peek tubing was dry-packed with zinc powder $(<150$ micron, Sigma Aldrich, Hamburg, Germany) and connected between the analytical column and the fluorescence detector. A vortexer and a refrigerated centrifuge were used for liquidliquid extraction. The lipid compounds were separated using a solid-phase extraction vacuum manifold.

\section{Reagents, Disposables and Standards}

The analytical reagent zinc acetate $(99.99 \%)$ was obtained from Sigma-Aldrich (Hamburg, Germany). Acetic acid was purchased from VWR International (Darmstadt, Germany). Solvents such as methanol, $n$-hexane, 2-propanol, ethanol, diethylether, and water were HPLC grade (LiChrosolv ${ }^{\circledR}$ ) and were obtained from VWR (Darmstadt, Germany).
Disposable SPE Cartridges Chromabond ${ }^{\circledR} \mathrm{SiOH} 3 \mathrm{~mL} / 500$ mg were supplied by Macherey-Nagel (Düren, Germany). Vitamin $\mathrm{K}$, i.e. phylloquinone and menaquinone-4, with a purity of $99 \%$ were purchased from Sigma-Aldrich (Hamburg, Germany). The internal standard (ISTD) vitamin $\mathrm{K} 1(25)$ [23] routinely used was obtained as a $10 \mathrm{mg} / \mathrm{mL}$ solution as a generous gift from Dr. Schurgers, University of Maastricht, the Netherlands. Konakion ${ }^{\circledR}$ MM 2 mg was purchased from Roche (Grenzach-Wyhlen, Germany).

\section{Preparation of Standards and Control Materials}

All solutions and dilutions including $\mathrm{K}$ vitamins were prepared using $100 \%$ HPLC grade solvents and were shielded from UV light. All standards - vitamin K1, MK-4, K1(25) (ISTD) - were dissolved in 100\% HPLC-grade 2-propanol to gain a concentration of $10 \mathrm{mg} / \mathrm{mL}$. The purity of the stock solutions and authenticity of the compounds was confirmed by gas chromatography-mass spectrometry [24]. Stock solutions were further diluted with 2-propanol and working solutions of $\mathrm{K} 1$ and MK-4 were prepared at concentrations ranging from 0.0625 to $20 \mathrm{ng}$ per absolute injection (10 calibration points). The primary stock solution of ISTD was $1000 \mathrm{ng} / \mathrm{mL}$. Dilutions of the primary stock were prepared at concentrations ranging between 25 and $100 \mathrm{ng} / \mathrm{mL}$. An appropriate amount of ISTD was added to the calibration solutions of $\mathrm{K} 1$ and $\mathrm{MK}-4$ as well as to the samples for analysis to gain a final concentration of $0.5,1$ or $2 \mathrm{ng}$ ISTD per absolute injection depending on the expected vitamin $\mathrm{K}$ concentration. Working standard solutions were stored at $20^{\circ} \mathrm{C}$ and were stable for at least two months.

A serum pool was obtained from at least six healthy volunteers and stored at $-80^{\circ} \mathrm{C}$ before analysis. For validation studies and as qualifiers by performing vitamin $\mathrm{K}$ analysis, pool samples were enriched to increase the basal concentration of phylloquinone and MK-4 by 0.1, 1, 10 and $100 \mathrm{ng}$ per absolute injection. Prior to performing the vitamin $\mathrm{K}$ determination assay, the internal standard was added to each serum sample.

\section{Subjects, Study Design and Pharmaceutical Formula- tions}

Blood samples were obtained by venipuncture from one female (30 yrs.) and one male (52 yrs.) healthy volunteer after vitamin $\mathrm{K} 1$ administration. The study was performed in conformance with the Declaration of Helsinki ethical guidelines as reflected in an a-priori-approval by the Local Ethic Committee of the Medical Faculty of the Rheinische Friedrich-Wilhelms University Bonn. Both probands were healthy according to medical history, physical examination and standard laboratory procedures. The subjects took no medication for 10 days prior to enrolment and during the course of the study. They were in a fasted state when Konakion ${ }^{\circledR} \mathrm{MM}$ was administered. Ten hours after dosing, standardized food was served.

Various pharmacokinetic parameters after two routes of administering Konakion ${ }^{\circledR}$ MM 2 mg were compared. The trial procedure started with a single oral intake of $2 \mathrm{mg} \mathrm{Ko-}$ nakion ${ }^{\circledR} \mathrm{MM}$ followed by a wash-out period of seven days and was continued with a single intravenous administration of the same dosage. The i.v. injection was carried out into a vein of one forearm, opposite to the one from which blood 
samples were taken. Blood samples (à $7.5 \mathrm{~mL}$ ) were collected into serum gel tubes (Sarstaedt, Nümbrecht, Germany) to $24 \mathrm{~h}$ upon p.o. and i.v. administration: at 1, 2, 2.5, 3, 3.5, $4,4.5,5,5.5,6,6.5,7,7.5,8,9,10,24 \mathrm{hrs}$. after p.o. intake, and at 2, 5, 10, 20, 30, 40, $50 \mathrm{~min}$. and at 1, 1.5, 2, 2.5, 3, $3.5,4,4.5,5,5.5,6,7,8,9,10,24$ hrs. after i.v. injection. During the first ten hours blood was collected through a peripherous vein catheter. Serum was separated immediately by centrifugation at $2250 \mathrm{~g}$ for $10 \mathrm{~min}$ at $18^{\circ} \mathrm{C}$ and stored at $20^{\circ} \mathrm{C}$ for around six months with no further freeze-thaw cycles prior to analysis. The samples were protected from light. The whole experiment was repeated after a time period of two years with the same two volunteers and under the same conditions as described above.

\section{Vitamin K Serum Determination Assay}

Vitamin $\mathrm{K}$ compounds were extracted from serum by liquid-liquid extraction. Aliquots of $0.5 \mathrm{~mL}$ serum samples were transferred to a disposable glass centrifuge tube $(16 \mathrm{x}$ $100 \mathrm{~mm}$ ) containing $0.5 \mathrm{~mL}$ bidestilled water. An appropriate amount of internal standard $(0.5,1$ or $2 \mathrm{ng}$ per absolute injection) was added. Two $\mathrm{mL}$ of ethanol were added to precipitate the proteins with brief agitation. After vortexing for $30 \mathrm{sec}, 4 \mathrm{~mL}$ of $n$-hexane were added and the contents were mixed vigorously. Centrifugation at $1500 \mathrm{~g}(\sim 3000 \mathrm{rpm})$ for 10 minutes at room temperature supported separation of the upper hexane layer from the lower aqueous-ethanolic layer and precipitated proteins. The upper hexane layer was quantitatively transferred to a disposable glass tube. The lower layer was additionally re-extracted with further $4 \mathrm{~mL}$ of hexane as described above. The upper organic layers were pooled and then evaporated to dryness under a gentle stream of nitrogen at $50^{\circ} \mathrm{C}$.

Isolation of the vitamin $\mathrm{K}$ fraction from lipid extracts was carried out by using solid phase extraction (SPE) system. SPE Sep-Pak ${ }^{\text {TM }}$ silica cartridges (Chromabond ${ }^{\circledR}$ SiOH 3 $\mathrm{ml} / 500 \mathrm{mg}$, Macherey-Nagel, Düren, Germany) were preconditioned with $9 \mathrm{~mL}$ of hexane $(3 \times 3 \mathrm{~mL})$ in order to remove materials from the cartridge interfering otherwise with the vitamin $\mathrm{K}$ assay. The dried lipid extract was dissolved in $2 \mathrm{~mL}$ of $\mathrm{n}$-hexane and pushed through the cartridge, the tube was rinsed with further $2 \mathrm{~mL}$ of hexane. Nine $\mathrm{mL}$ of hexane ( $3 \times 3 \mathrm{~mL}$ ) were drawn through each cartridge under vacuum to separate the hydrocarbon lipid fraction and the eluate was discarded. Retained vitamin $\mathrm{K}$ compounds were eluted with $9 \mathrm{~mL}(3 \times 3 \mathrm{~mL})$ of $3 \%(3 / 97, \mathrm{v} / \mathrm{v})$ diethylether in hexane and collected in disposable glass tubes $(16$ x $100 \mathrm{~mm})$. Eluates were evaporated to dryness under a stream of nitrogen at $50^{\circ} \mathrm{C}$.

The dried vitamin $\mathrm{K}$ fraction was dissolved in $50 \mu \mathrm{L} 2-$ propanol and transferred to $200 \mu \mathrm{L}$ glass vials for HPLC analysis. A volume of $40 \mu \mathrm{L}$ was injected onto the column via a valve injector. $\mathrm{K}$ vitamins, all in the nonfluorescent quinone forms, were separated by isocratic HPLC system on Reversed Phase-C18 column and were then converted to their fluorescent hydroquinone forms by post-column zinc reduction. The mobile phase contained, per litre, $880 \mathrm{~mL}$ methanol, $100 \mathrm{~mL}$ acetonitrile, $1.1 \mathrm{~g}$ zinc acetate, $10 \mathrm{~mL}$ acetic acid and $10 \mathrm{~mL}$ water. The flow rate was $0.8 \mathrm{~mL} / \mathrm{min}$ and the detection wavelengths were $246 \mathrm{~nm}$ excitation, 430 $\mathrm{nm}$ emission.

\section{Method Validation and KEQAS Participation}

The modified HPLC method for vitamin $\mathrm{K}$ analysis in serum samples with fluorescence detection after post-column zinc reduction was validated according to the guidances for Bioanalytical Method Validation [25, 26]. Fundamental parameters to ensure the acceptability of the method performance regarding specificity, selectivity, range of determination, linearity, accuracy, precision, reproducibility, and stability were assessed. To prove the acceptability of the method, analyses of blank propanolic samples without vitamin $\mathrm{K}$ and of pool serum samples containing only the endogenous vitamin $\mathrm{K}$ basal concentration as well as of pool serum samples spiked with $\mathrm{K} 1$ and MK-4 were conducted in sextuple. The serum pool was obtained from at least six healthy volunteers. Pool samples were enriched to increase the basal concentration of phylloquinone and MK-4 by 0.1 , 1,10 and $100 \mathrm{~K} 1$ and MK-4 ng per absolute injection. Prior to performing the vitamin $\mathrm{K}$ determination assay, an adequate amount of internal standard was added to each serum sample.

Participation in the UK Vitamin K External Quality Assurance Scheme (KEQAS), coordinated by Drs. Harrington and Card at the Nutristasis Unit, The Centre for Haemostasis and Thrombosis, St. Thomas Hospital, London, permitted a comparison between the present assay and those already being used by other laboratories world-wide. Different robin round samples, covering a wide range of values within the range encountered in human serum or plasma were analyzed. The target for results was $\pm 20 \%$ deviation from the ALTM (all laboratory trimmed mean representing the target concentration) which was based on previous performance.

\section{Calculations and Statistical Evaluation}

Linear regression, mean, and standard deviation (S.D.) were calculated by using Microsoft Excel 2007. The precision of the assay was defined as the coefficient of variation (CV) of at least six repeats. The limit of detection (LOD) and limit of quantification (LOQ) was based on signal-to-noise ratio. A signal-to-noise ratio of 3:1 was considered acceptable for estimating the LOD, wheareas the LOQ was based on signal-to-noise ratio of at least 10:1.

Pharmacokinetic evaluation was carried out on the basis of the data from the experiments on vitamin K1 pharmacokinetics using WinNonlin (version 5.2.1, Pharsight Corp.) as a standard program. Noncompartmental analysis of the serum concentration $v s$ time profiles after oral and intravenous administration of $2 \mathrm{mg}$ Konakion ${ }^{\circledR} \mathrm{MM}$ was done for both volunteers and both experiments. Serum concentration-time data of vitamin $\mathrm{K} 1$ was considered as the primary variable as well as the evaluation of pharmacokinetic parameters including maximum serum concentration $\left(\mathrm{C}_{\max }\right)$, time of the maximum serum concentration $\left(\mathrm{t}_{\max }\right)$, area under the curve (AUC), bioavailabilty $\left(\mathrm{F}_{\text {p.o. }}\right)$, clearance $(\mathrm{CL})$, volume of distribution at steady state $\left(\mathrm{V}_{\mathrm{ss}}\right)$, terminal half-life $\left(\mathrm{t}_{1 / 2}\right)$. Some of the main pharmacokinetic parameters could be directly taken from the data such as $\mathrm{C}_{\max }$ and $\mathrm{t}_{\max }$. The area under the plasma concentration $v s$ time curve from time zero extrapolated to infinity was calculated by:

$$
\mathrm{AUC}=\mathrm{AUC}_{0-\mathrm{t}}+\mathrm{C}_{\text {last }} / \lambda_{\mathrm{z}}
$$


$\mathrm{AUC}_{0-\mathrm{t}}$ is the area under the plasma concentration versus time curve from time zero to the last sampling time at which the plasma concentration is at, or above, the limit of quantification (LOQ). The calculation was performed by using the lin-log trapezoidal method. $\mathrm{C}_{\text {last }}$ is the observed plasma concentration at the last sampling time at which plasma concentrations are at, or above, the LOQ.

The terminal (first-order) elimination rate constant $\left(\lambda_{z}\right)$ was calculated from the slope of the terminal linear portion of the $\log$ concentration $v s$ time curve by linear regression analysis.

The volume of distribution at steady-state was calculated as:

$$
\mathrm{V}_{\mathrm{ss}}=\mathrm{MRT} \times \mathrm{CL}
$$

where MRT is the mean residence time calculated by $\mathrm{AUMC}_{\text {i.v. }} / \mathrm{AUC}_{\text {i.v. }}$, and $\mathrm{AUMC}_{\text {i.v. }}$ is the area under the first moment curve from zero extrapolated to infinity following intravenous administration. AUMC was calculated as:

$$
\mathrm{AUMC}=\mathrm{AUMC}_{0-\mathrm{t}}+\mathrm{C}_{\text {last }} \times \mathrm{t}_{\text {last }} / \lambda_{\mathrm{z}}+\mathrm{C}_{\text {last }} / \lambda_{\mathrm{z}}{ }^{2} .
$$

The absolute bioavailability upon oral administration of Konakion ${ }^{\circledR}$ MM was calculated as:

$$
\mathrm{F}_{\text {p.o. }}=\mathrm{AUC}_{\text {p.o. }} / \mathrm{AUC}_{\text {i.v. }} \times \text { Dose }_{\text {i.v. }} / \text { Dose }_{\text {p.o. }} \times 100 \%
$$

The systemic clearance was calculated according to the equation:

$$
\mathrm{CL}=\text { Dose }_{\text {i.v. }} / \mathrm{AUC}_{\text {i.v. }} \text {. }
$$

The terminal half-lives $\left(t_{1 / 2}\right)$ were calculated using the terminal elimination rate constant as:

$$
\mathrm{t}_{1 / 2}=0.693 / \lambda_{\mathrm{z}} \text {. }
$$

The plasma concentration values were corrected for endogenous vitamin $\mathrm{K}$ levels in each subject by subtraction of individual pre-dose value from all post-dose values. The plasma concentration was set to zero on some instances were such correction resulted in small negative values.

\section{RESULTS}

\section{Validation of the HPLC Method for Vitamin K Determi- nation in Human Serum}

\section{Specificity, Selectivity}

The modified HPLC method for vitamin K serum determination showed the ability to differentiate and quantify unequivocally vitamin $\mathrm{K} 1$ and $\mathrm{MK}-4$ in presence of other compounds in biological samples. The retention time of $\mathrm{K}$ vitamins (HPLC) under particular conditions and their mass spectra (GC-MS) were considered to be reasonably unique to identify the different substances. An authentic HPLC chromatogram of a spiked serum extract containing vitamin $\mathrm{K} 1$, MK-4 and K1(25), the internal standard, is shown in Fig. (1). Both, K1 and MK-4 as well as the internal standard were clearly and precisely separated from each other. In addition, there were no interfering compounds found after the serum preparation for analysis. The authenticity of $\mathrm{K}$ vitamins was proved by GC-MS using full scan mode $(50-600 \mathrm{~m} / \mathrm{z})$ [24]. Fig. (2A-C) presents the characteristic mass spectra specific for phylloquinone, menaquinone-4, and the internal standard K1(25), respectively.

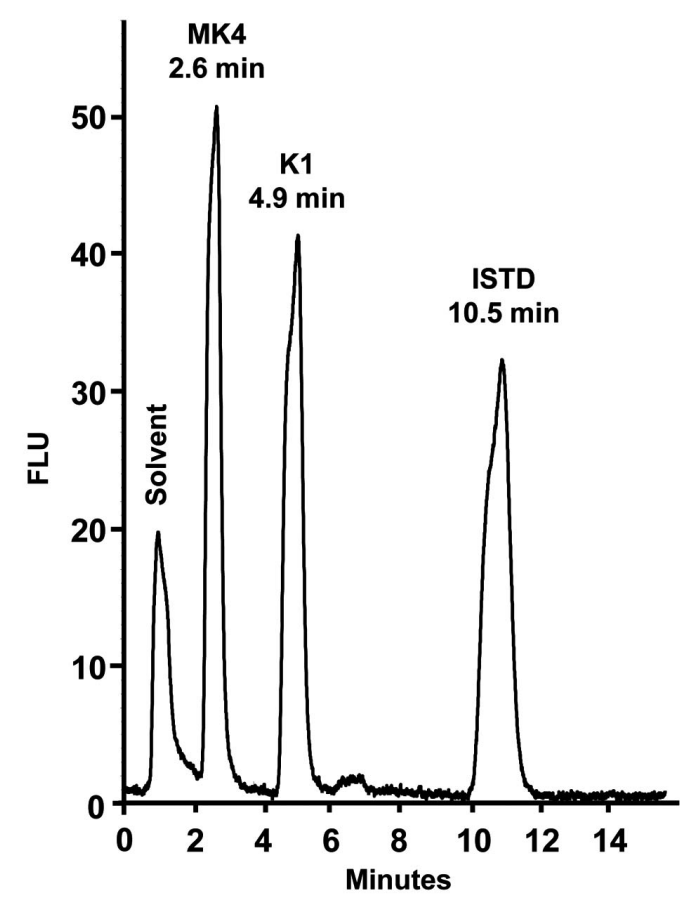

Fig. (1). HPLC chromatogram of phylloquinone (K1), menaquinone-4 (MK4), and vitamin K1(25) (ISTD), FLU (Fluorescent signal intensity).

\section{Range of Determination}

\section{Limit of Detection (LOD)}

Determination of the signal-to-noise ratio was performed by comparing measured signals (abundance) from samples with the lowest concentration of an analyte with the abundance of the baseline in the surrounding of the vitamin $\mathrm{K}$ peak. A signal-to-noise ratio of 3:1 was considered acceptable for estimating the detection limit according to the guidelines. The LOD that could be distinguished from the absence of the substances reached $0.015 \mathrm{ng} \mathrm{mL}^{-1} \mathrm{~K} 1$ and MK-4.

\section{Limit of Quantification (LOQ), Lower Limit of Quantifica- tion $(L L O Q)$}

The LOQ averaged to $0.0625 \mathrm{ng}$ for both, K1 and MK-4 per absolute injection. The LOQ was based on signal-tonoise ratio of 10:1. LLOQ also met the required conditions since the analyte response at the LLOQ was at least 5 times the response compared to blank response and the analyte peak was identifiable, discrete, and reproducible with a precision of $20 \%$ and accuracy of $80-120 \%$. The lowest standard on the calibration curve equal to $0.0625 \mathrm{ng} \mathrm{K} 1$ and MK4 per absolute injection was accepted as the LLOQ.

\section{Linearity and Quantification}

Calibration curves were constructed by plotting the weight ratios of vitamin $\mathrm{K}$ to ISTD against the peak area ratios of vitamin $\mathrm{K}$ to ISTD. The curves were judged linear if the correlation coefficient $r^{2}$ was $>0.99$ as calculated by the weighted linear regression. The concentrations of the calibration standards were back-calculated in order to confirm the suitability of the used calibration model of linear regression. At least four out of six non-zero standards including the LLOQ and the calibration standard at the highest concentra- 
A

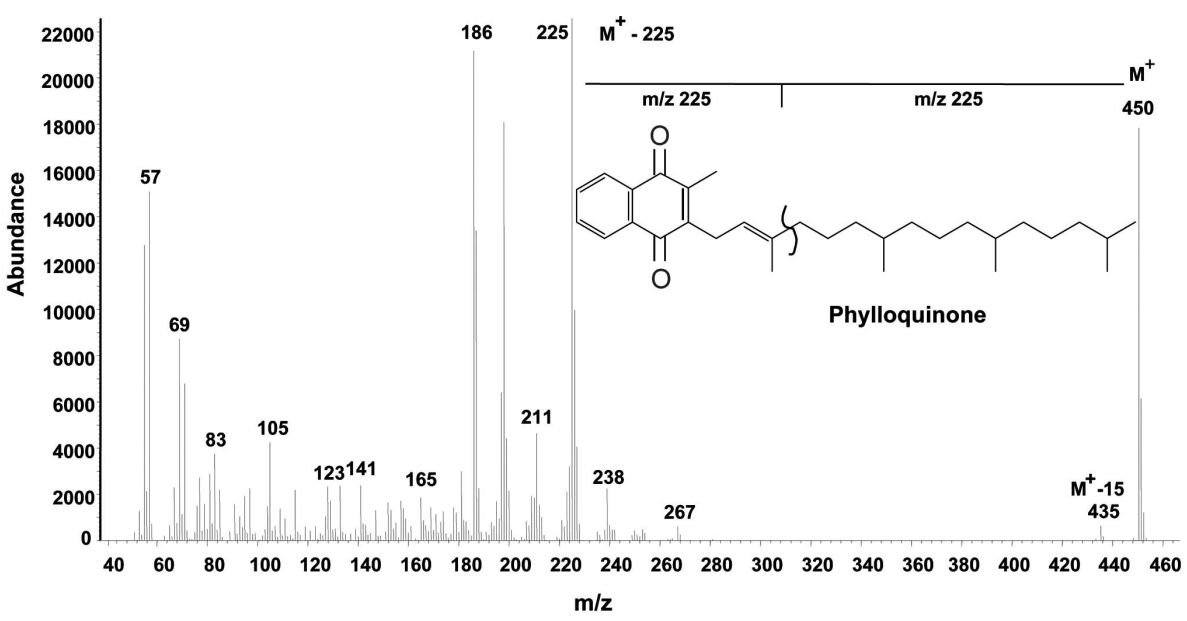

B
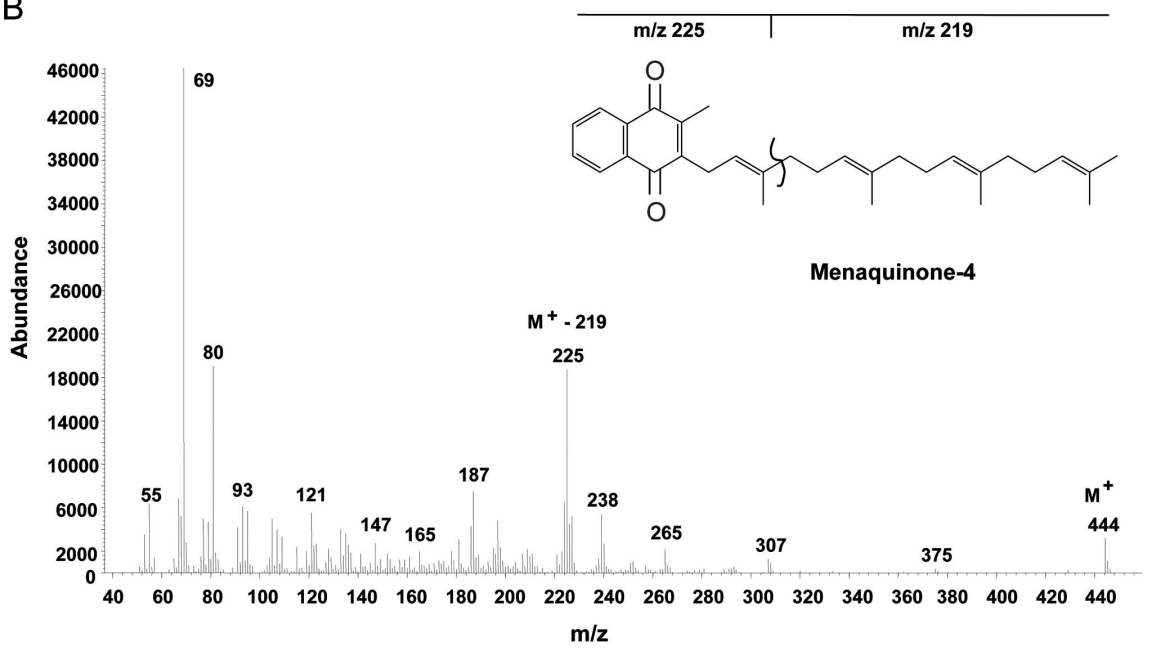

C

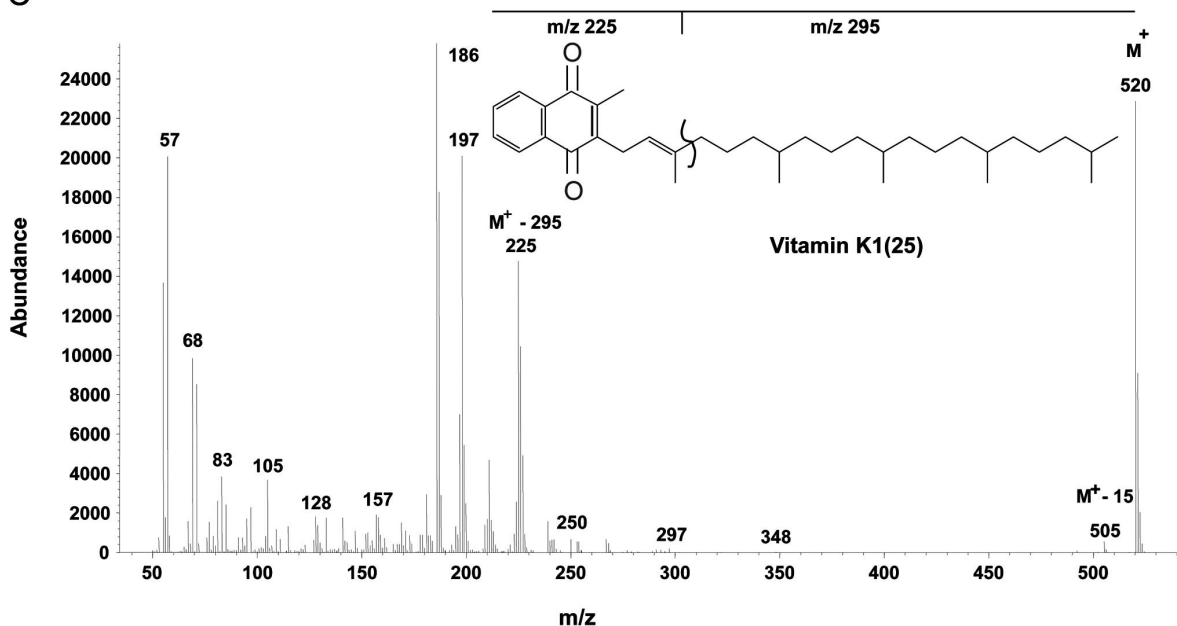

Fig. (2). Full scan mass spectra of phylloquinone (K1) (A), menaquinone-4 (MK-4) (B), and vitamin K1(25) (ISTD) (C).

tion, showed a deviation of the interpolated concentrations of standards in the daily calibration curves of $\mathrm{K} 1$ and MK-4 within the acceptable range of $85-115 \%(80-120 \%$ for LLOQ). Two concentration ranges of vitamin K1 and MK-4 were used for quantification during validation analyses: concentration range $I$ with calibration points $1-6(0.0625,0.125$, $0.250,0.500,1$ and $2 \mathrm{ng} \mathrm{K} 1$ and MK-4 per absolute injection), and concentration range II with calibration points 5-10
$(1,2,5,10,15$ and $20 \mathrm{ng} \mathrm{K1}$ and MK-4 per absolute injection). Samples containing vitamin $\mathrm{K}$ concentration higher than $20 \mathrm{ng}$ per absolute injection were further diluted to gain substance concentration in the range described above.

\section{Accuracy - External Quality Assurance}

Three batches each with three samples from the Vitamin K External Quality Assurance Assessment Scheme 
(KEQAS) [27] were analyzed in 2010 in our laboratory without a knowledge of the other participants` results. Thereby, each batch contained two plasma samples and one ethanolic standard. Within KEQAS, the performance of participating groups was assessed by comparison of each group's percentage absolute difference from the ALTM representing the target concentration, in consideration of the fact that there is no particular reference laboratory stated and no gold standard method for vitamin $\mathrm{K}$ analysis defined. The target standard deviation was $20 \%$ from the mean. In the overall inter-laboratory assessment for low and high vitamin $\mathrm{K}$ serum concentrations, our group achieved a deviation ranging between 1.0 and 1.5 -fold from the ALTM.

\section{Precision, Recovery}

To assess the precision and recovery of the method, six replicates per concentration for spiked serum samples were analyzed three times on the same day and once a day during three days within a week in order to determine the intra- and interday-reproducibility, respectively. The precision of the method at each concentration was calculated as the coefficient of variation $(\mathrm{CV})$. The recovery was estimated by com- paring analytical results for extracted samples at different concentrations with unextracted samples that represent $100 \%$ recovery. The precision determined at each concentration level did not exceed $15 \%$ of the CV except for the LLOQ, where it did not exceed $20 \%$ of the CV (Tables 1, 2). An overall mean for each examined concentration $(n=6)$ and each intraday measurement $(\mathrm{n}=3$, batch $I, I I, I I I)$ revealed a $\mathrm{CV}$-value of $5.8 \pm 2.7 \%$ and $8.5 \pm 2.9 \%$ for $\mathrm{K} 1$ and MK-4, respectively. The intraday recovery averaged to $102 \pm 9.3 \%$ for K1 and $105 \pm 9.1 \%$ for MK-4 (Table 1). The interday experiments resulted in a CV-value of $4.6 \pm 2.1 \%$ and $6.1 \pm 3.7 \%$ for $\mathrm{K} 1$ and MK-4, respectively, while the estimated interday recovery averaged to $105 \pm 5.1 \%$ for $\mathrm{K} 1$ and $101 \pm 9.7 \%$ for MK-4 across the different concentrations within the three days (Table 2). These results enabled the consideration of the method for vitamin $\mathrm{K}$ determination in human serum as precise and good reproducible.

\section{Internal Quality Assurance}

Quality control was warranted by analyzing a batch of low, medium and high vitamin $\mathrm{K}$ concentration in each sequence of samples. A batch run was accepted and the data

Table 1. Intraday Reproducibility for Phylloquinone (Vitamin K1) and Menaquinone-4 (MK-4)

\begin{tabular}{|c|c|c|c|c|c|c|c|c|c|c|c|c|}
\hline \multicolumn{7}{|c|}{ K1 } & \multicolumn{6}{|c|}{ MK-4 } \\
\hline \multirow{2}{*}{$\begin{array}{l}\text { Batch }^{\text {a) }} \\
\text { [ng/inj.] }\end{array}$} & I & II & III & $\mathbf{I}$ & II & III & I & II & III & $\mathbf{I}$ & II & III \\
\hline & \multicolumn{3}{|c|}{$\mathrm{CV}[\%]^{\mathrm{b})}$} & \multicolumn{3}{|c|}{ Recovery $[\%]^{\mathbf{b}}$} & \multicolumn{3}{|c|}{$\mathrm{CV}[\%]^{\mathrm{b})}$} & \multicolumn{3}{|c|}{ Recovery [\% $]^{\mathrm{b})}$} \\
\hline 0.25 & 3.9 & 2.9 & 2.0 & 106 & 107 & 105 & 6.7 & 7.2 & 9.4 & 89 & 90 & 105 \\
\hline 1 & 2.4 & 1.5 & 4.1 & 99 & 92 & 86 & 7.1 & 2.6 & 6.9 & 90 & 98 & 90 \\
\hline 10 & 2.5 & 11.7 & 9.5 & 100 & 102 & 108 & 3.0 & 11.6 & 13.6 & 99 & 96 & 110 \\
\hline$*$ & 4.4 & 5.0 & 5.8 & 95 & 98 & 95 & 4.6 & 3.6 & 5.9 & 100 & 97 & 98 \\
\hline$* *$ & 5.5 & 4.2 & 7.9 & 101 & 106 & 108 & 8.8 & 4.6 & 9.2 & 112 & 114 & 113 \\
\hline$* * *$ & 8.4 & 3.8 & 5.5 & 107 & 105 & 109 & 14.4 & 2.7 & 5.9 & 111 & 110 & 112 \\
\hline
\end{tabular}

${ }^{a)}$ three runs within one day (batch I-III).

${ }^{b)}$ mean of six replicates per concentration.

*basal serum concentration $\mathrm{K} 1+1 \mathrm{ng} / \mathrm{inj}$. K1 and MK-4.

**basal serum concentration $\mathrm{K} 1+10 \mathrm{ng} / \mathrm{inj}$. $\mathrm{K} 1$ and MK-4

***basal serum concentration $\mathrm{K} 1+100 \mathrm{ng} / \mathrm{inj}$. K1 and MK-4.

Table 2. Interday Reproducibility for Phylloquinone (Vitamin K1) and Menaquinone-4 (MK-4)

\begin{tabular}{|c|c|c|c|c|c|c|c|c|c|c|c|c|}
\hline \multicolumn{7}{|c|}{ K1 } & \multicolumn{6}{|c|}{ MK-4 } \\
\hline Batch $^{\text {a) }}$ & I & II & III & I & II & III & I & II & III & I & II & III \\
\hline [ng/inj.] & \multicolumn{3}{|c|}{$\mathrm{CV}[\%]^{\mathrm{b})}$} & \multicolumn{3}{|c|}{ Recovery [\%] ${ }^{\text {b) }}$} & \multicolumn{3}{|c|}{ CV [\%] ${ }^{b)}$} & \multicolumn{3}{|c|}{ Recovery $[\%]^{\text {b) }}$} \\
\hline 0.25 & 10.1 & 4.8 & 4.9 & 109 & 97 & 105 & 4.9 & 7.7 & 3.4 & 92 & 95 & 89 \\
\hline 1 & 2.9 & 4.2 & 5.2 & 96 & 105 & 100 & 2.7 & 6.8 & 11.6 & 86 & 89 & 88 \\
\hline 10 & 4.4 & 3.2 & 7.6 & 104 & 100 & 100 & 9.9 & 2.8 & 13.6 & 95 & 94 & 109 \\
\hline$*$ & 5.4 & 5.9 & 4.6 & 107 & 106 & 114 & 9.7 & 7.3 & 3.8 & 109 & 102 & 109 \\
\hline$* *$ & 3.6 & 2.8 & 5.8 & 113 & 112 & 105 & 11.2 & 2.0 & 1.8 & 109 & 113 & 112 \\
\hline$* * *$ & 4.2 & 1.4 & 1.3 & 105 & 108 & 103 & 4.2 & 2.4 & 3.8 & 105 & 99 & 114 \\
\hline
\end{tabular}

a) one run per day (batch I-III) within a week.

${ }^{b)}$ mean of six replicates per concentration.

*basal serum concentration $\mathrm{K} 1+1 \mathrm{ng} / \mathrm{inj}$. K1 and MK-4.

**basal serum concentration $\mathrm{K} 1+10 \mathrm{ng} / \mathrm{inj}$. K1 and MK-4.

***basal serum concentration $\mathrm{K} 1+100 \mathrm{ng} / \mathrm{inj}$. $\mathrm{K} 1$ and MK-4. 
underwent further analysis when the relative error did not exceed 15\% (20\% for LLOQ) for more than two-thirds of the samples.

\section{Stability}

Stability testing of K vitamins (MK-4, K1) was performed in serum and stock solution. For stability in serum, spiked serum samples were analyzed in triplicate. The substances of interest were considered stable if more than $85 \%$ were retained at the end of the study period; for the lowest and highest quantifiable concentration $80-120 \%$ recovery were accepted. CV values of lower than $20 \%$ were required. The freeze and thaw stability was determined after 3 refreeze and thaw cycles when three aliquots of the low and high concentration were stored at $-80^{\circ} \mathrm{C}$ for 24 hours and thawed unassisted at room temperature. The samples were analyzed immediately on the third cycle and the corresponding results are shown in Table 3. In testing short-term stability, three aliquots of each of the low and high concentrations were thawed at room temperature, kept at this temperature for five hours and analyzed (Table $\mathbf{3}$ ). The long-term stability (Table 4) at $-80^{\circ} \mathrm{C}$ frozen human serum was determined by storing three aliquots of each of the low and high concentrations under the same conditions and periodic analysis over six months (batches I-IV: analysis immediately, after 1, 3 and 6 months storage at $-80^{\circ} \mathrm{C}$, respectively). The stock solution stability of $\mathrm{K}$ vitamins and the internal standard was evaluated by storing the solutions under defined conditions and subsequent analysis of the samples. The storage occurred at room temperature when exposed at daylight or kept in the dark for six hours, or samples were frozen at $-20^{\circ} \mathrm{C}$ for six hours prior to analysis. The post-preparative stability was assessed over a period of 24 hours run time. Processed serum samples and stock solutions containing K1 and MK-4 were found to be stable at $10^{\circ} \mathrm{C}$ in the autosampler for at least 24 hours. CV and recovery values were within the acceptable range as stated above.

\section{Pharmacokinetics of Konakion ${ }^{\circledR}$ MM after p.o. and i.v. Administration}

Two human volunteers, one female (volunteer A) and one male (volunteer B), were investigated in this exploratory pharmacological study. Pharmacokinetic analysis after p.o. and i.v. administration of $2 \mathrm{mg}$ Konakion ${ }^{\circledR} \mathrm{MM}$ was performed for both participants. Fig. (3A-D) represents vitamin K1 serum concentrations, expressed on a logarithmic scale, $v s$ time profiles, obtained after p.o. intake of $2 \mathrm{mg} \mathrm{Ko-}$ nakion ${ }^{\circledR} \mathrm{MM}$ in two experiments in a two-year follow-up for volunteer $A\left(A_{1, \text { p.o. }}\right.$ and $\left.A_{2, \text { p.o. }}\right)$ and volunteer $B\left(B_{1, \text { p.o. }}\right.$ and $\left.B_{2, \text { p.o. }}\right)$. Serum concentrations $v s$ time profiles from both i.v. experiments are shown in Fig. (4A-D) for subject $A\left(A_{1, i . v .}\right.$ and $\left.A_{2, \text { i.v. }}\right)$ and subject $B\left(B_{1, \text { i.v. }}\right.$ and $\left.B_{2, \text { i... }}\right)$. Measured phylloquinone concentrations varied between the volunteers as well as when both experiments were compared.

Pharmacokinetic parameters obtained after i.v. and p.o. administration of $2 \mathrm{mg}$ Konakion ${ }^{\circledR} \mathrm{MM}$ to volunteer $\mathrm{A}$ and volunteer B in both experiments in a two-year follow-up are shown in Table 5. The maximum concentration $\left(\mathrm{C}_{\max }\right)$ and the time point of $\mathrm{C}_{\max }\left(\mathrm{t}_{\max }\right)$ of $\mathrm{K} 1$ serum concentration after oral and intravenous administration of Konakion ${ }^{\circledR} \mathrm{MM} 2 \mathrm{mg}$ were determined from the raw data.

In volunteer $\mathrm{A}, \mathrm{t}_{\max }$ amounted to $120 \mathrm{~min}$ for $\mathrm{A}_{1, \text { p.o. }}$ and to 135 min for $A_{2, \text { p.o. }}$ AUC was lower following p.o. administration as compared to i.v. administration, as is reflected by $\mathrm{F}_{\text {p.o. }}$ of $54 \%$ and $80 \%$ in the first and second experiment, respectively. Hence, $\mathrm{F}_{\text {p.o. }}$ was 1.5 -fold higher when the

Table 3. Freeze and Thaw (Three Cycles) and Short-Term (Five Hours) Stability of Phylloquinone (K1) and Menaquinone-4 (MK4)

\begin{tabular}{|c|c|c|c|c|c|c|c|c|}
\hline \multicolumn{5}{|c|}{ Freeze and thaw } & \multicolumn{4}{|c|}{ Short-term } \\
\hline \multirow[b]{2}{*}{ [ng/inj.] } & K1 & MK-4 & K1 & MK-4 & K1 & MK-4 & K1 & MK-4 \\
\hline & \multicolumn{2}{|c|}{$\mathrm{CV}[\%]^{\text {a) }}$} & \multicolumn{2}{|c|}{ Recovery [\%] ${ }^{\text {a) }}$} & \multicolumn{2}{|c|}{$\mathrm{CV}[\%]^{\text {a) }}$} & \multicolumn{2}{|c|}{ Recovery $[\%]^{\text {a) }}$} \\
\hline 0.1 & 0.9 & 1.4 & 91 & 81 & 5.3 & 7.9 & 92 & 83 \\
\hline 20 & 10.4 & 10.3 & 117 & 111 & 8.7 & 10.9 & 112 & 112 \\
\hline$* *$ & 9.7 & 14.1 & 87 & 90 & 6.0 & 13.4 & 89 & 96 \\
\hline
\end{tabular}

${ }^{a)}$ mean of three replicates per concentration.

**basal serum concentration K1 + $10 \mathrm{ng} / \mathrm{inj}$. K1 and MK-4.

Table 4. Long-Term (Six Months) Stability of Phylloquinone (K1) and Menaquinone-4 (MK-4)

\begin{tabular}{|c|c|c|c|c|c|c|c|c|c|c|c|c|c|c|c|c|}
\hline \multicolumn{9}{|c|}{ K1 } & \multicolumn{8}{|c|}{ MK-4 } \\
\hline [ng/inj.] & \multicolumn{4}{|c|}{$\mathrm{CV}[\%]^{\mathrm{b})}$} & \multicolumn{4}{|c|}{ Recovery [\%] ${ }^{\text {b) }}$} & \multicolumn{4}{|c|}{$\mathrm{CV}[\%]^{\mathrm{b})}$} & \multicolumn{4}{|c|}{ Recovery [\% ${ }^{b)}$} \\
\hline 0.1 & 0.9 & 5.2 & 2.9 & 2.1 & 91 & 92 & 103 & 84 & 1.4 & 6.5 & 5.5 & 2.6 & 81 & 85 & 82 & 81 \\
\hline 20 & 10.4 & 3.5 & 1.7 & 3.5 & 117 & 96 & 107 & 88 & 10.3 & 5.1 & 1.3 & 7.6 & 111 & 96 & 103 & 85 \\
\hline
\end{tabular}

a) analysis immediately, after 1,3 and 6 months storage at $-80^{\circ} \mathrm{C}$ (batches I-IV).

b) mean of three replicates per concentration.

**basal serum concentration $\mathrm{K} 1+10 \mathrm{ng} / \mathrm{inj} . \mathrm{K} 1$ and MK-4. 
A

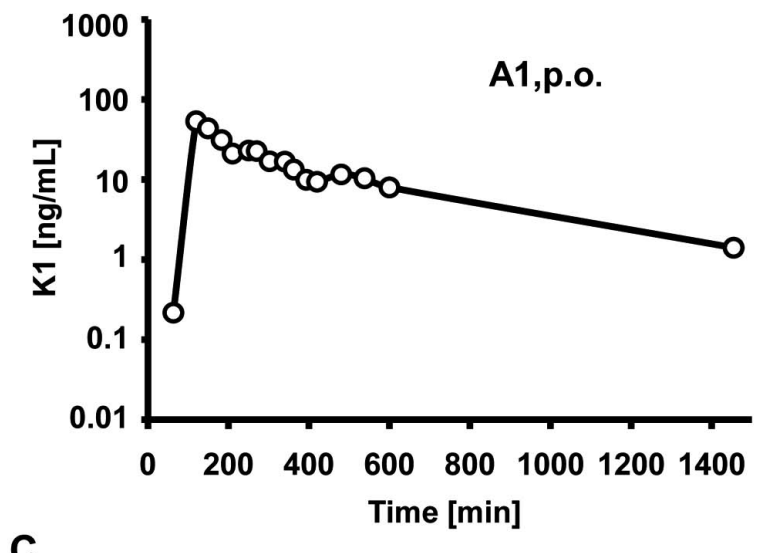

C

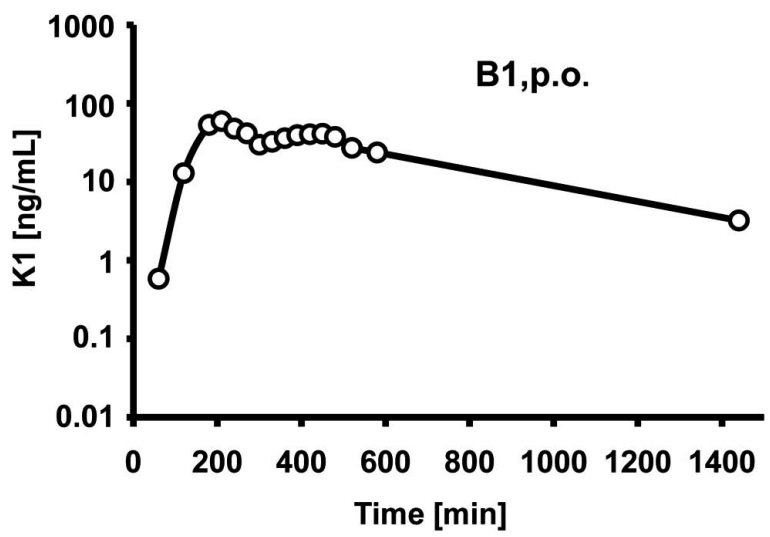

B

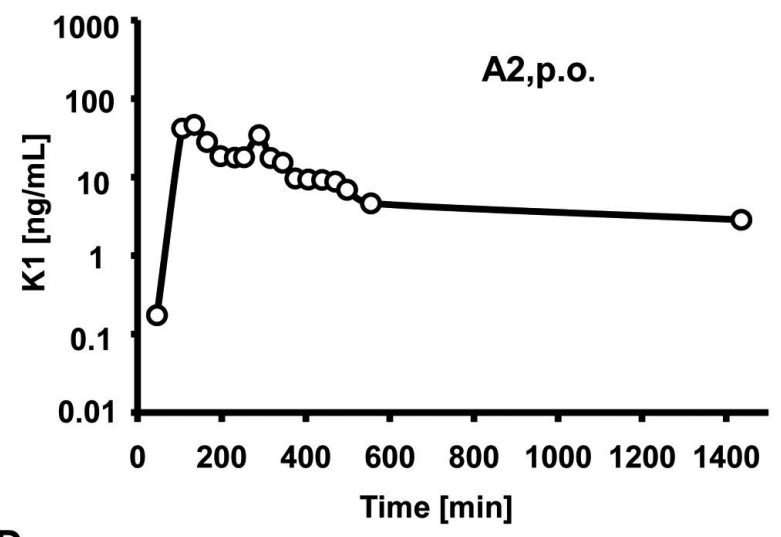

D

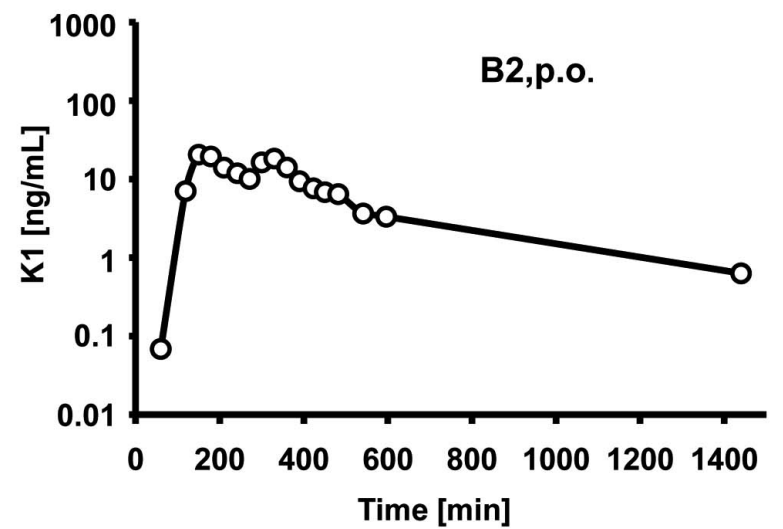

Fig. (3). A-D. Serum concentration (log scale) vs time profiles of vitamin K1, obtained from two volunteers $\mathbf{A}$ and $\mathbf{B}$ following p.o. administration of Konakion ${ }^{\circledR}$ MM 2 mg in two experiments in a two-year follow-up.

A

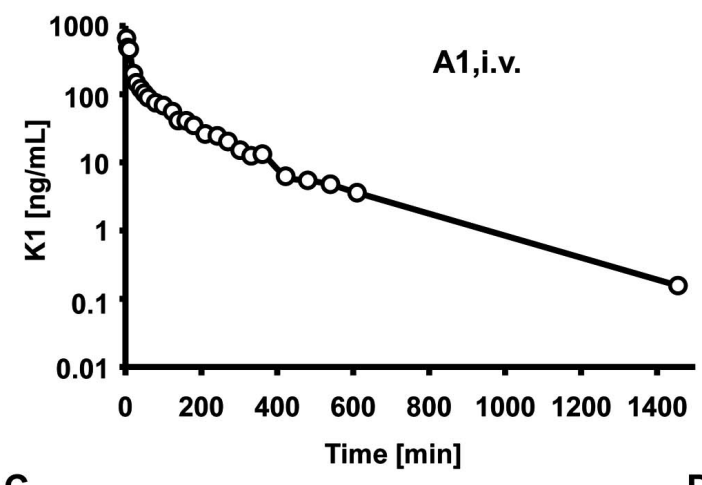

C

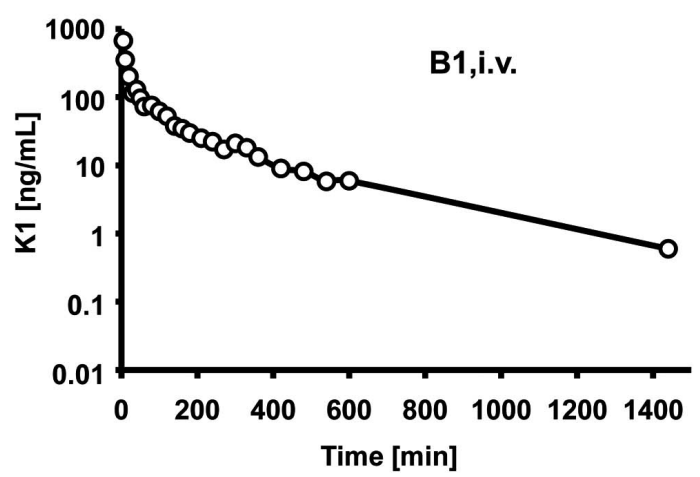

B

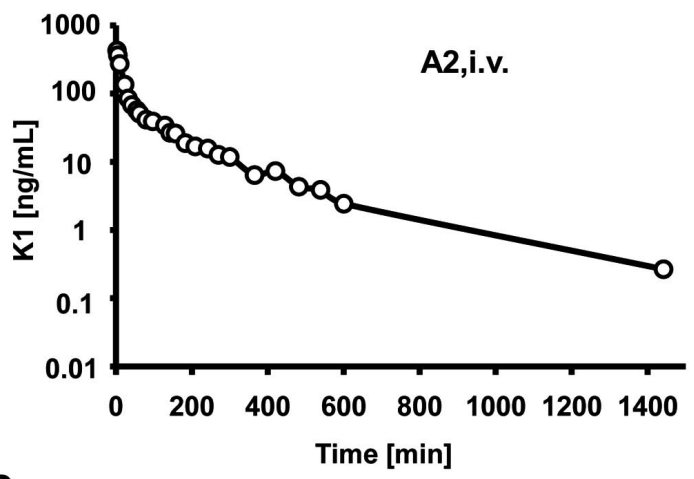

D

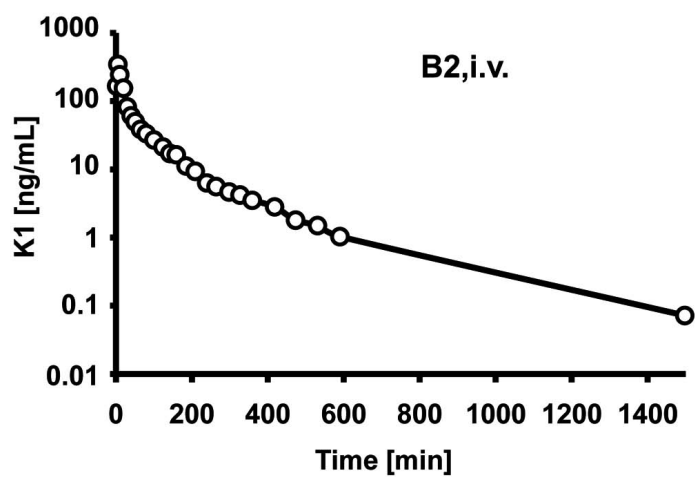

Fig. (4). A-D. Serum concentration (log scale) vs time profiles of vitamin K1, obtained from two volunteers A and B following i.v. administration of Konakion ${ }^{\circledR}$ MM $2 \mathrm{mg}$ in two experiments in a two-year follow-up. 
Table 5. Pharmacokinetic Parameters Obtained After i.v. and p.o. Administration of Konakion ${ }^{\circledR}$ MM, 2 mg Vitamin K1 (Phytomenadione), to Volunteer A and Volunteer B in Two Experiments in a Two-Year Follow-Up

\begin{tabular}{|c|c|c|c|c|}
\hline volunteer $\mathbf{A}$ & \multicolumn{2}{|c|}{ i.v. vitamin K1 } & \multicolumn{2}{|c|}{ p.o. vitamin $\mathrm{K} 1$} \\
\hline $\mathrm{C}_{\max }\left[\mathrm{ng} \mathrm{mL} L^{-1}\right]$ & & & 53 & 46 \\
\hline $\mathrm{AUC}\left[\mathrm{ng} \mathrm{h} \mathrm{mL} \mathrm{L}^{-1}\right]$ & 438 & 294 & 237 & 234 \\
\hline $\mathrm{V}_{\mathrm{ss}}[\mathrm{L}]$ & 10 & 17 & & \\
\hline $\mathrm{CL}^{*}\left[\mathrm{~mL} \min ^{-1}\right]$ & 76 & 113 & 140 & 142 \\
\hline $\mathrm{t}_{1 / 2}[\mathrm{~min}]$ & 175 & 215 & 323 & 386 \\
\hline volunteer B & $\mathbf{B}_{1, \text { i.v. }}$ & $\mathbf{B}_{2, \text { i.v. }}$ & $\mathbf{B}_{\text {1,p.o. }}$ & $\mathbf{B}_{2, \text { p.o. }}$ \\
\hline $\mathrm{AUC}\left[\mathrm{ng} \mathrm{h} \mathrm{mL} L^{-1}\right]$ & 479 & 220 & 464 & 116 \\
\hline $\mathrm{F}_{\text {p.o. }}[\%]$ & & & 97 & 53 \\
\hline $\mathrm{V}_{\mathrm{ss}}[\mathrm{L}]$ & 12 & 15 & & \\
\hline $\mathrm{CL}^{*}\left[\mathrm{~mL} \min ^{-1}\right]$ & 70 & 152 & 72 & 287 \\
\hline $\mathrm{t}_{1 / 2}[\mathrm{~min}]$ & 231 & 201 & 316 & 255 \\
\hline
\end{tabular}

* $\mathrm{CL} / \mathrm{F}$ following oral administration.

experiment was repeated after two years. Similar changes in comparison with the first experiment were noted for $\mathrm{V}_{\mathrm{ss}}(1.7$ fold higher), CL (1.5-fold higher), and the terminal half-lives (1.2-fold longer for both i.v. and p.o.).

In Volunteer $\mathrm{B}, \mathrm{t}_{\max }$ amounted to $210 \mathrm{~min}$ for $\mathrm{B}_{1 \text {,p.o. and }}$ 150 min for $B_{2, \text { p.o. }}$. As opposed to subject $A, F_{\text {p.o. }}$ in subject $B$ was 1.6-fold lower when the experiment was repeated after two years. Changes in comparison with the first experiment were also seen for $\mathrm{V}_{\mathrm{ss}}$ (1.3-fold higher), CL (2.2-fold higher), and terminal half-lives (1.2-fold shorter for both i.v. and p.o.).

\section{DISCUSSION}

\section{Bioanalytical Method Validation of Vitamin K1 and MK- 4 Serum Determination}

The modified HPLC method for vitamin $\mathrm{K}$ analysis in serum samples with fluorescence detection after post-column zinc reduction was validated according to the guidances for Bioanalytical Method Validation [25, 26] of the International Conference of Harmonization. The main purpose was to investigate the utility of the method to simultaneously define the kinetics of vitamin $\mathrm{K} 1$ and measure the extent to which oral doses are absorbed.

A number of HPLC assays using various detection systems have been reported. These include UV [28, 29], electrochemical [28, 30], electrofluorimetric [28], mass spectrometric [31] and postcolumn chemical reduction with fluorescence detection $[20,32,33]$. The latter technique has been shown to be inherently selective, sensitive, and reproducible[20, 32]. Postcolumn chemical reduction of $\mathrm{K}$ vitamins is usually achieved by using a zinc reducer systemmetallic/ionic zinc $[20,32,33]$. This system suffers from an impediment upon exhaustion of the supply of zinc in the reducer column. The shrinking zinc particles pass through the reducer column frits that limits the useful life of the reducer column and releases damaging particles into the HPLC system, leading to baseline shifts. In our experience, the zinc reducer column had to be replaced after every batch run of 40 samples to maintain optimal reduction and chromatographic performance which was proved to be sufficient for our purpose of use regarding pharmacokinetics of vitamin K1 within 24 hours after single-dose administration. The method was used for analysis of up to 40 serum samples during a day and shows additionally the versatility by working with human serum or plasma as well as with organic tissues. The reported methods for the extraction of vitamin $\mathrm{K}$ from plasma or serum are labor intensive, all requiring multiple extraction procedures to remove lipophilic interferences. The single solid-phase extraction procedure for sample cleanup and concentration of vitamin $\mathrm{K}$ compounds, including the internal standard K1(25), showed good effectiveness with no interference from impurities and endogenous compounds. The internal standard is a structural analog of phylloquinone [20,32] and not present in biological material. The phylloquinone and menaquinone- 4 peaks and that of internal standard were well separated during chromatographic analysis from matrix signals both in serum or plasma. The identity of the analyte was confirmed by the 
tests mentioned above. Intra- and interday repeatability was adequate as well as recovery testing. For the serum, a limit of detection of $0.03 \mathrm{nmol} / \mathrm{L}(0.015 \mathrm{ng} / \mathrm{mL})$ was found, which indicates about 3-fold higher sensitivity compared to assays, previously reported [20, 30, 32-34].

The method fulfilled all analytical standard criteria. It provided high specificity for $\mathrm{K}$ vitamins that could be directly detected without conversion to other derivatives. We examined recovery and accuracy using pool serum. Each peak of the vitamin $\mathrm{K}$ analogs was clearly resolved as a single peak within a separation time of 20 minutes. These results proved the system to be reliable and reproducible for the measurement of serum vitamin $\mathrm{K}$. The reliability of the HPLC method was evaluated based on the variation in retention times. The relative standard deviation, calculated from retention times obtained from over 40 injections, proved to be less than $1 \%$ for all compounds, indicating good chromatographic stability. The assay provides a rapid and relatively easy-to-use approach to the quantification of vitamin $\mathrm{K}$ ana$\log$ in human serum without compromising assay sensitivity and shows good reproducible results within the acceptable ranges regarding each particular validation parameter.

To prove and warrant the practical applicability of the method for vitamin K serum determination described as External Quality Assurance, our laboratory participated in robin-round tests. Our results, compared to the corresponding KEQAS consensus means, were indicative of good to very good performance. To what extent the other participating groups basically yield low- or high-leaning values, depended in the main on the used method for vitamin $\mathrm{K}$ analysis.

First Application of the HPLC Method in a Pharmacological Study on the Pharmacokinetics of Vitamin K1

As first application of the HPLC method for vitamin K serum determination served analysis of samples from an exploratory study on the pharmacokinetics of vitamin $\mathrm{K} 1$. We are aware of the limitation of these preliminary results due to the low number of participants.

There are only a few reports about direct measurements of serum concentrations of vitamin $\mathrm{K}$ after oral, intravenous or intramuscular single-dose administration [35-39]. As soon as sensitive analytical methods for vitamin $\mathrm{K}$ determination were introduced [28-29, 32-33], information on the kinetics of phylloquinone became available. The methods showed sufficient sensitivity to enable detection of vitamin $\mathrm{K} 1$ in $\mathrm{pg}$ $\mathrm{mL}^{-1}$ range and thus allowed profiling of phylloquinone levels for many hours to days after administration.

Our study of the i.v. and p.o. pharmacokinetics of vitamin $\mathrm{K} 1$ as Konakion ${ }^{\circledR}$ MM 2 mg showed considerable differences between both repeated dosing occasions and between subjects. The pharmacokinetic results were indicative of intra- and inter-subject variability. The general shape of plasma concentration-time curves following p.o. (Fig. 3A-D) and i.v (Fig. 4A-D) administration remained similar during the two year interval although the systemic exposure in terms of $\mathrm{C}_{\max }$ and AUC showed changes. The i.v. plasma concentration-time curves showed a biexponential decline, suggesting a short initial distribution phase followed by an elimination phase. The curves obtained after p.o. route of administration showed an initial absorption phase with a roughly monoexponential decay after $\mathrm{C}_{\max }$ was reached. However, there was also a second distinct maximum following $\mathrm{C}_{\max }$ which is typical for substances undergoing enterohepatic circulation.

The mean clearance rate of 95 and $111 \mathrm{~mL} \mathrm{~min}^{-1}$ for volunteer $\mathrm{A}$ and $\mathrm{B}$, respectively, found in our experiments is within the range of those that were calculated from previous data of phylloquinone behavior upon injection which varied

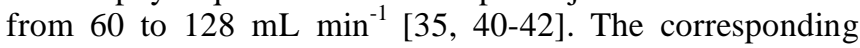
mean terminal half-lives of $3.5 \mathrm{~h}$ after i.v. administration and $5.4 \mathrm{~h}$ after p.o. intake were also well comparable with previously published data [35]. Interestingly, phylloquinone serum half-lives in patients with severe acute liver disease were approximately two-fold longer than those found in subjects with normal hepatic function [38]. Furthermore, terminal half-lives of vitamin $\mathrm{K} 1$ in newborns were also considerably longer compared to adults [37].

Oral administration of phylloquinone revealed substantial inter- and intra-individual variations in the bioavailability of this compound. Comparing both experiments, a considerable increase from $54 \%$ to $80 \%$ for volunteer $\mathrm{A}$ and a decrease from $97 \%$ to $53 \%$ for volunteer B was noted during the twoyear interval. The differences in volunteer $B$ might have been caused by significant loss of body weight and change in life-style. Hence, observed differences may be explained by intra- and inter-individual variation in dietary intake, transport and uptake of vitamin $\mathrm{K}$ as well as in lipoprotein metabolism, especially regarding triglyceride-enriched lipoproteins (VLDL) $[14,43]$ and other determinants of vitamin $\mathrm{K}$ status. All these findings affirm the importance of standardizing trial procedures including co-medication when performing pharmacokinetic experiments.

\section{CONCLUSION}

We report on the validation of a highly sensitive, accurate, robust and reliable HPLC method for the determination of vitamin $\mathrm{K}$ serum concentrations. The ability to intrinsically quantify vitamin $\mathrm{K}$ in human serum has the potential to advance pharmacokinetic studies.

\section{ACKNOWLEDGEMENTS}

The authors acknowledge Stefanie Jarmer for skillful technical assistance. The Clinical Study Support Center (CSSC) of the Institute of Clinical Chemistry and Clinical Pharmacology, University Clinics Bonn, Germany, was also acknowledged for its support.

\section{CONFLICT OF INTEREST STATEMENT}

\section{Authors' Conflict of Interest Disclosure}

The authors state that there are no conflicts of interest regarding the publication of this article. Research funding played no role in the study design; in the collection, analysis, and interpretation of data; in the writing of the report; or in the decision to submit the report for publication.

\section{REFERENCES}

[1] Shearer, M. J.; Vitamin, K. Lancet, 1995, 345(8944), 229-234.

[2] Shearer, M. J. Role of vitamin K and Gla proteins in the pathophysiology of osteoporosis and vascular calcification. Curr. Opin. Clin. Nutr. Metab. Care, 2000, 3(6), 433-438.

[3] Furie, B.; Furie, B. C. Molecular basis of vitamin K-dependent gamma-carboxylation. Blood, 1990, 75 (9), 1753-1762. 
[4] Oldenburg, J.; Marinova, M.; Muller-Reible, C.; Watzka, M. The vitamin K cycle. Vitam. Horm., 2008, 78, 35-62.

[5] Oldenburg, J.; Watzka, M.; Rost, S.; Muller, C. R. VKORC1: molecular target of coumarins. J. Thromb. Haemost., 2007, 5(Suppl 1), 1-6.

[6] Rost, S.; Fregin, A.; Ivaskevicius, V.; Conzelmann, E.; Hortnagel, K.; Pelz, H. J.; Lappegard, K.; Seifried, E.; Scharrer, I.; Tuddenham, E. G.; Muller, C. R.; Strom, T. M.; Oldenburg, J. Mutations in VKORC1 cause warfarin resistance and multiple coagulation factor deficiency type 2 . Nature, 2004, 427(6974), 537541.

[7] Shapiro, A. D.; Jacobson, L. J.; Armon, M. E.; Manco-Johnson, M. J.; Hulac, P.; Lane, P. A.; Hathaway, W. E. Vitamin K deficiency in the newborn infant: prevalence and perinatal risk factors. $J$. Pediatr., 1986, 109(4), 675-680.

[8] Suttie, J. W. Vitamin K and human nutrition. J. Am. Diet. Assoc., 1992, 92(5), 585-590.

[9] Thijssen, H. H.; Vervoort, L. M.; Schurgers, L. J.; Shearer, M. J. Menadione is a metabolite of oral vitamin K. Br. J. Nutr., 2006, 95(2), 260-266.

[10] Davidson, R. T.; Foley, A. L.; Engelke, J. A.; Suttie, J. W. Conversion of dietary phylloquinone to tissue menaquinone-4 in rats is not dependent on gut bacteria. J. Nutr., 1998, 128(2), 220223

[11] Shearer, M. J.; McBurney, A.; Barkhan, P. Studies on the absorption and metabolism of phylloquinone (vitamin K1) in man. Vitam. Horm., 1974, 32, 513-542.

[12] Savage, D.; Lindenbaum, J. Clinical and experimental human vitamin K deficiency. 1983, 271-320.

[13] Kohlmeier, M.; Saupe, J.; Drossel, H. J.; Shearer, M. J. Variation of phylloquinone (vitamin K1) concentrations in hemodialysis patients. Thromb. Haemost., 1995, 74, (5), 1252-1254.

[14] Lamon-Fava, S.; Sadowski, J. A.; Davidson, K. W.; O'Brien, M. E.; McNamara, J. R.; Schaefer, E. J. Plasma lipoproteins as carriers of phylloquinone (vitamin K1) in humans. Am. J. Clin. Nutr., 1998, 67(6), 1226-1231.

[15] Schurgers, L. J.; Vermeer, C. Differential lipoprotein transport pathways of K-vitamins in healthy subjects. Biochim. Biophys. Acta, 2002, 1570(1), 27-32.

[16] Roche Konakion MM 2 mg. Fachinformation, 2007.

[17] Roche Konakion MM 10 mg. Fachinformation, 2007.

[18] Booth, S.; Tucker, K.; McKeown, N.; Davidson, K.; Dallal, G.; Sadowski, J. Relationships between dietary intakes and fasting plasma concentrations of fat-soluble vitamins in humans. J. Nutr., 1997, 127(4), 587-592.

[19] Sadowski, J. A.; Hood, S. J.; Dallal, G. E.; Garry, P. J. Phylloquinone in plasma from elderly and young adults: factors influencing its concentration. Am. J. Clin. Nutr., 1989, 50(1), 100108.

[20] Haroon, Y.; Bacon, D. S.; Sadowski, J. A. Liquid-chromatographic determination of vitamin $\mathrm{K} 1$ in plasma, with fluorometric detection. Clin. Chem., 1986, 32(10), 1925-1929.

[21] Dolnikowski, G. G.; Sun, Z.; Grusak, M. A.; Peterson, J. W.; Booth, S. L. HPLC and GC/MS determination of deuterated vitamin $\mathrm{K}$ (phylloquinone) in human serum after ingestion of deuterium-labeled broccoli. J. Nutr. Biochem., 2002, 13(3), 168174.

[22] Haroon, Y.; Bacon, D. S.; Sadowski, J. A. Chemical reduction system for the detection of phylloquinone (vitamin K1) and menaquinones (vitamin K2). J. Chromatogr., 1987, 384, 383-389.

[23] Koivu-Tikkanen, T. J.; Ollilainen, V.; Piironen, V. I. Determination of phylloquinone and menaquinones in animal products with fluorescence detection after postcolumn reduction with metallic zinc. J. Agric. Food Chem., 2000, 48(12), 6325-6331.

[24] Lutjohann, D.; Stroick, M.; Bertsch, T.; Kuhl, S.; Lindenthal, B.; Thelen, K.; Andersson, U.; Bjorkhem, I.; Bergmann Kv, K.; Fassbender, K. High doses of simvastatin, pravastatin, and cholesterol reduce brain cholesterol synthesis in guinea pigs. Steroids, 2004, 69(6), 431-438.

[25] FDA Bioanalytical Method Validation. 2001.
[26] Shah, V. P.; Midha, K. K.; Findlay, J. W.; Hill, H. M.; Hulse, J. D.; McGilveray, I. J.; McKay, G.; Miller, K. J.; Patnaik, R. N.; Powell, M. L.; Tonelli, A.; Viswanathan, C. T.; Yacobi, A. Bioanalytical method validation--a revisit with a decade of progress. Pharm. Res., 2000, 17(12), 1551-1557.

[27] Card, D. J.; Shearer, M. J.; Schurgers, L. J.; Harrington, D. J. The external quality assurance of phylloquinone (vitamin $\mathrm{K}(1)$ ) analysis in human serum. Biomed. Chromatogr., 2009, 23(12), 1276-1282.

[28] Langenberg, J. P.; Tjaden, U. R. Determination of (endogenous) vitamin $\mathrm{K} 1$ in human plasma by reversed-phase high-performance liquid chromatography using fluorometric detection after postcolumn electrochemical reduction. Comparison with ultraviolet, single and dual electrochemical detection. J. Chromatogr., 1984, 305(1), 61-72.

[29] Shearer, M. J. Assay of K vitamins in tissues by high-performance liquid chromatography with special reference to ultraviolet detection. Methods Enzymol., 1986, 123, 235-51.

[30] McCarthy, P. T.; Harrington, D. J.; Shearer, M. J. Assay of phylloquinone in plasma by high-performance liquid chromatography with electrochemical detection. Methods Enzymol., 1997, 282, 421-33.

[31] Fu, X.; Peterson, J. W.; Hdeib, M.; Booth, S. L.; Grusak, M. A.; Lichtenstein, A. H.; Dolnikowski, G. G. Measurement of deuterium-labeled phylloquinone in plasma by high-performance liquid chromatography/mass spectrometry. Anal. Chem., 2009, 81, (13), 5421-5

[32] Davidson, K. W.; Sadowski, J. A. Determination of vitamin K compounds in plasma or serum by high-performance liquid chromatography using postcolumn chemical reduction and fluorimetric detection. Methods Enzymol., 1997, 282, 408-21.

[33] Wang, L. Y.; Bates, C. J.; Yan, L.; Harrington, D. J.; Shearer, M. J.; Prentice, A. Determination of phylloquinone (vitamin K1) in plasma and serum by HPLC with fluorescence detection. Clin. Chim. Acta, 2004, 347(1-2), 199-207.

[34] Azharuddin, M. K.; O'Reilly D. S.; Gray, A.; Talwar, D. HPLC method for plasma vitamin k1: effect of plasma triglyceride and acute-phase response on circulating concentrations. Clin. Chem., 2007, 53(9), 1706-13.

[35] Soedirman, J. R.; De Bruijn, E. A.; Maes, R. A.; Hanck, A.; Gruter J. Pharmacokinetics and tolerance of intravenous and intramuscular phylloquinone (vitamin $\mathrm{K} 1$ ) mixed micelles formulation. $\mathrm{Br} . J$. Clin. Pharmacol., 1996, 41(6), 517-23.

[36] Jones, K. S.; Bluck, L. J.; Wang, L. Y.; Coward, W. A. A stable isotope method for the simultaneous measurement of vitamin $\mathrm{K}(1)$ (phylloquinone) kinetics and absorption. Eur. J. Clin. Nutr., 2008, 62(11), 1273-81

[37] Raith, W.; Fauler, G.; Pichler, G.; Muntean, W. Plasma concentrations after intravenous administration of phylloquinone (vitamin $\mathrm{K}(1)$ ) in preterm and sick neonates. Thromb. Res., 2000 , 99(5), 467-72.

[38] Pereira, S. P.; Rowbotham, D.; Fitt, S.; Shearer, M. J.; Wendon, J.; Williams, R. Pharmacokinetics and efficacy of oral versus intravenous mixed-micellar phylloquinone (vitamin K1) in severe acute liver disease. J. Hepatol., 2005, 42(3), 365-70.

[39] Pereira, S. P.; Shearer, M. J.; Williams, R.; Mieli-Vergani, G. Intestinal absorption of mixed micellar phylloquinone (vitamin K1) is unreliable in infants with conjugated hyperbilirubinaemia: implications for oral prophylaxis of vitamin $\mathrm{K}$ deficiency bleeding. Arch. Dis. Child Fetal. Neonatal. Ed., 2003, 88(2), F113-8.

[40] Choonara, I. A.; Scott, A. K.; Haynes, B. P.; Cholerton, S.; Breckenridge, A. M.; Park, B. K. Vitamin K1 metabolism in relation to pharmacodynamic response in anticoagulated patients. Br. J. Clin. Pharmacol., 1985, 20(6), 643-8.

[41] Bjornsson, T. D.; Meffin, P. J.; Swezey, S. E.; Blaschke, T. F. Effects of clofibrate and warfarin alone and in combination on the disposition of vitamin K1. J. Pharmacol. Exp. Ther., 1979, 210(3), 322-6.

[42] Bechthold, H. Untersuchungen zum Vitamin K1-Stoffwechsel beim Menschen, 1985.

[43] Shearer, M. J.; Newman, P. Metabolism and cell biology of vitamin K. Thromb. Haemost., 2008, 100(4), 530-47. 